\title{
Effect of Preservation Methods on Physicochemical Quality, Phenolic Content, and Antioxidant Activity of Stevia Leaves
}

\author{
Nadia Hidar (iD, ${ }^{1}$ Abdelhamid Noufid, ${ }^{2}$ Ayoub Mourjan, ${ }^{3}$ El Mustapha El Adnany, ${ }^{1}$ \\ Safa Mghazli, ${ }^{4}$ Mohammed Mouhib, ${ }^{5}$ Abderrahim Jaouad, ${ }^{1}$ and Mostafa Mahrouz ${ }^{1}$ \\ ${ }^{1}$ SCIMATOP (LICVEDD) Laboratory of Innovation and Sustainable Development \& Expertise in Green Chemistry, \\ Department of Chemistry, Cadi Ayyad University, Marrakesh, Morocco \\ ${ }^{2}$ Department of Civil Engineering, National School of Applied Sciences (ENSA), Ibn Zohr University, Agadir, Morocco \\ ${ }^{3}$ Laboratory of Valorization and Safety of Food Products, Faculty of Sciences and Technics, University Sultan Moulay Slimane, \\ Beni Mellal, Morocco \\ ${ }^{4}$ Laboratoire des Bioressources et Sécurité Sanitaire des Aliments, Cadi Ayyad University, Marrakesh, Morocco \\ ${ }^{5}$ Unité de Recherche sur Les Techniques Nucléaires de L'Environnement et La Qualité (URTNEQ), \\ Centre Régional de La Recherche Agronomique de Tanger, 78 Bd Sidi Med Ben Abdellah, 90000 Tangier, Morocco
}

Correspondence should be addressed to Nadia Hidar; nadia.hidar@gmail.com

Received 14 May 2021; Revised 30 November 2021; Accepted 9 December 2021; Published 23 December 2021

Academic Editor: Muhammad Imran

Copyright (C) 2021 Nadia Hidar et al. This is an open access article distributed under the Creative Commons Attribution License, which permits unrestricted use, distribution, and reproduction in any medium, provided the original work is properly cited.

\begin{abstract}
The effect of freeze-drying and gamma irradiation at $0.5,1$, and $2 \mathrm{kGy}$ on the physicochemical composition (moisture, fat, ash, mineral, and chlorophyll contents), microstructure, total phenolic content, and antioxidant capacity of stevia leaves was investigated in the present study. The results obtained indicated that freeze-drying and gamma irradiation treatments caused significant reduction $(p \leq 0.05)$ of moisture and fat contents in comparison with those of commercial leaves, while ash content was not significantly affected. Mineral composition was analysed. Among the analysed elements, potassium and iron levels were higher in the freeze-dried and irradiated samples, respectively. The microstructure was analysed using a scanning electron microscope. Micrographs revealed that a higher porous size structure was obtained by freeze-drying, and degradation of cell wall structure was more clearly visualized by irradiation at $2 \mathrm{kGy}$. However, the main functional groups were stable as confirmed by Fourier transform infrared spectroscopy analysis. The effects on chlorophyll content, phenolic profile, and antioxidant properties were evaluated before and after ten months of storage. In terms of chlorophyll contents, the freeze-dried leaves exhibited the highest content. Chlorophylls a and b decreased when storage progressed for freeze-dried leaves as well as for gamma-irradiated leaves. Both preservation methods gave significant advantages in increasing the total phenolic content and DPPH scavenging activity. Moreover, a significant increase of bioactive compounds and antioxidant activity was observed as the gamma irradiation dose increased. In addition, the storage time increased the amounts of polyphenols and DPPH scavenging activity. After 10 months of storage, gamma-irradiated leaves had the highest total phenolic content as well as the DPPH scavenging activity followed by freeze-dried leaves. The results indicate that freeze-drying and gamma irradiation at the studied doses could be effective postharvest methods for preservation of stevia leaf quality.
\end{abstract}

\section{Introduction}

Stevia (Stevia rebaudiana Bertoni), native to Brazil and Paraguay, is a genus of appropriately 200 species of perennial herbs belonging to the Asteraceae family $[1,2]$. The leaves of stevia contain sweetening compounds called steviol glycosides, and the most abundant are stevioside and rebaudioside A which are nearly 300 times sweeter than sugar; their intense sweetness has made them significant scientific and commercial interest worldwide [3, 4]. In Morocco, the culture of stevia was officially introduced for the first time in 2008. Since then, this plant was grown by smallholders or at an experimental level by several public or private institutions, within research programs [5]. 
Stevia leaves as a natural sweetener are used as sugar and artificial sweetener substitutes resulting in the increasing harmful health impacts of sugars such as obesity and diabetes [1]. Some of the artificial sweeteners such as aspartame, saccharin, acesulfame-K, neotame, and sucralose with their extensive utilization lead to fatal maladies such as cancer and phenylketonuria [2].

Assessment of the microbiological quality of stevia from local markets in Jordan revealed its contamination with aerobic mesophilic bacteria and fungi [6]. For the prevention of microbial contamination and the production of high quality of medicinal and aromatic plants (MAPs), several technologies exist for the preservation of MAPs, among which are freeze-drying and gamma irradiation. Freezedrying produces the highest quality food product obtainable by any drying method. Despite unmatched advantages, freeze-drying has always been considered the most expensive operation for manufacturing a dehydrated product owing to high energy consumption and high costs of both operation and maintenance [7]. It is well known that freezedrying can retain the original color, aroma, taste, shape, and nutrients of fruits and vegetables to the utmost extent. However, the shortcomings of its long drying time and high energy consumption limit its wide application [8].

Radiation is a physical treatment for the preservation of many different types of food commodities. Being a cold process, irradiation can ensure shelf-life extension and eliminate microbial contamination while retaining the color, flavor, taste, and aroma of the food product [9]. A joint expert committee convened by the FAO/IAEA/WHO stated that irradiation of any food commodity up to $10 \mathrm{kGy}$ presents no toxicological hazard [10].

For preserving stevia leaves, some drying methods are applied. Lemus-Mondaca et al. [11] evaluated the influence of different drying techniques (convective drying and vacuum-, microwave-, infrared-, sun-, shade-, and freezedrying) on proximal analysis, vitamins $C$ and $E$, fatty acid and amino acid profiles, and steviosides from stevia leaves. Gasmalla et al. [12] determined the effect of three drying methods (sunlight for about 5 days, oven at $60^{\circ} \mathrm{C}$ for $16 \mathrm{~h}$, and microwave). Periche et al. [13] applied different drying conditions (hot-air-drying at $100^{\circ} \mathrm{C}$ and $180^{\circ} \mathrm{C}$, freeze-drying, and shade-drying). Hidar et al. [14] investigated the effect of solar convective drying on kinetics and quality attributes of stevia leaves grown in Morocco. In addition, the far-infrared-drying technique was used to dry Stevia rebaudiana leaves [15].

Aromatic and medicinal herbs are among the products submitted to decontamination assays based on irradiation treatment [16]. Aloysia citrodora P., Melissa officinalis L. and Melittis melissophyllum L. [16], Mentha piperita L. [17], Thymus vulgaris and Mentha pulegium [18], Rosmarinus officinalis [19], and Thymus satureioides [20] are among the studied plants, namely, submitted to gamma radiation. To date, there is no study available on the effects of gamma irradiation on stevia leaves. Thus, the aim of this study was to determine the effects of different processing methods (freeze-drying and gamma irradiation at low doses) on physicochemical quality and antioxidant activity of stevia leaves.

\section{Material and Methods}

2.1. Raw Material. Fresh and commercial dried Stevia rebaudiana Bertoni leaves used in this study were obtained from MOGADOR Cooperative (Essaouira, Morocco). Commercial samples were available as dried leaves for herbal infusion preparation.

\subsection{Methods}

2.2.1. Sample Preparation Procedure. In this study, freezedrying and gamma irradiation processes were applied on fresh and commercial stevia leaves, respectively.

(1) Freeze-Drying Process. Fresh stevia leaves were first frozen overnight and then freeze-dried for $24 \mathrm{~h}$ at $0.100 \mathrm{mbar}$ and $-50^{\circ} \mathrm{C}$ in a freeze-dryer (Christ ALPHA 1-2 LD plus, France).

(2) Gamma Irradiation Treatment. Gamma irradiation was carried out in a cobalt-60-based gamma chamber in the BOUKHALEF ionization station of the National Institute for Agricultural Research (Tangier, Morocco) at a dose rate of $5.14 \mathrm{kGy} / \mathrm{min}$. The samples were packed, sealed in polythene bags, and irradiated with low doses of $0.5,1$, and $2 \mathrm{kGy}$.

Following the preservation treatment, commercial (control), freeze-dried, and irradiated leaves were stored at room temperature, and all samples were evaluated at day 0 (treatment day) and 10 months after treatment.

2.2.2. Determination of Proximal Composition. Moisture, fat, and ash contents were determined according to the AOAC standard method [21].

2.2.3. Analysis of Chlorophyll $a$ and Chlorophyll $b$. Stevia chlorophyll was extracted by soaking $200 \mathrm{mg}$ of leaf sample in $4 \mathrm{~mL}$ of acetone-water mixture (90\%) for $5 \mathrm{~min}$ according to the method described by Hidar et al. [14]. The absorbance of the extracts at 630,645, and $665 \mathrm{~nm}$ was measured with a spectrophotometer (UV-2550, Shimadzu Corporation, Kyoto, Japan), and the chlorophyll contents were calculated using the following equations [22]:

(1) Chlorophyll a $(\mathrm{mg} / \mathrm{g})=11.6 *$ A665-1.31 * A645$0.14 * \mathrm{~A} 630$

(2) Chlorophyll b $(\mathrm{mg} / \mathrm{g})=-4.34 * \mathrm{~A} 665+20.7 * \mathrm{~A} 645-$ $4.42 * \mathrm{~A} 630$

where A665, A645, and A630 are the absorbance of the extracts at 665,645 , and $630 \mathrm{~nm}$, respectively. 
2.2.4. Analysis of Mineral Composition. The mineral composition of the samples was measured by X-ray diffraction using a portable XRF analyser (Olympus NDT, Waltham, USA) [23].

\subsubsection{Determination of Total Phenolic Compounds}

(1) Preparation of Phenolic Extract. The extracts used for the determination of total phenolic content were prepared according to the Hidar et al. [14] method.

(2) Determination of Total Phenolic Content. $50 \mu \mathrm{l}$ of the extract of the stevia leaves was mixed with $0.25 \mathrm{ml}$ of Folin-Ciocalteu reagent and $1.25 \mathrm{ml}$ of deionized water. The mixture was vortexed and kept at room temperature for $3 \mathrm{~min}$, and then $0.5 \mathrm{ml}$ of $20 \%$ sodium carbonate was added. The mixture was incubated at $40^{\circ} \mathrm{C}$ for $30 \mathrm{~min}$. The absorbance was measured at $750 \mathrm{~nm}$ using a spectrophotometer (UV-2550, Shimadzu Corporation, Kyoto, Japan). The content of total phenols was expressed in $\mathrm{mg}$ of gallic acid equivalent (GAE) per $1 \mathrm{~g}$ of stevia plant.

2.2.6. Determination of DPPH Radical Scavenging Activity. The free-radical scavenging effect was estimated according to the method of Periche et al. [13].

\subsubsection{FTIR Spectroscopy for Quantitative Analysis.} Fourier transform infrared (FTIR) spectra were plotted using VERTEX 70 (Bruker, VERTEX 70 DTGS, Germany) operating in the range of $4000-400 \mathrm{~cm}^{-1}$ with a resolution of $4 \mathrm{~cm}^{-1}$. The FTIR spectra were taken in the transmittance mode. The characterized discs consisted of dried stevia leaves previously ground and mixed thoroughly with potassium bromide in 1:99 (sample: $\mathrm{KBr}$ ) ratio, respectively.

2.2.8. Microstructure Analysis Using Scanning Electron Microscopy (SEM). In order to investigate the effect of preservation methods on the microscopic structure, the stevia leaves were analysed with a VEGA3 TESCAN scanning electron microscope (Tescan, Brno, Czech Republic). To stabilize the surface structure, the samples were carboncoated using a Cressington 108 carbon/A carbon coater. The acceleration voltage was set at $15 \mathrm{kV}$ in order to be sensitive to the extreme surface morphology.

2.2.9. Statistical Analysis. All analyses were performed at least in triplicate, and mean values were reported. IBM SPSS 20.0 software was used to perform the statistical analyses. When significant differences were observed $(p \leq 0.05)$, Tukey's test was used to determine the differences among the mean values.

\section{Results and Discussion}

3.1. Proximate Composition Determination. The results of proximal properties of stevia are presented in Table 1. The results showed that there were no significant differences $(p>0.05)$ in ash content; however, the moisture and fat contents decreased after freeze-drying and gamma irradiation. The fat content was lower at the end of the preservation processes. For gamma irradiation, the reduction in fat levels could have been caused by a reduced activity of the enzymes involved in the de novo synthesis of fatty acids induced by the irradiation treatment [24]. Besides, irradiation can cause fat oxidation [25].

In other study, Lemus-Mondaca et al. [11] found values of 10.5 and $9.86 \mathrm{~g} / 100 \mathrm{~g}$ for fat and ash contents for freezedried stevia, respectively. The results obtained are in agreement with those of previous work done by Khattak [26] who reported that the ash content was found to be the same for control and irradiated samples of Emblica officinalis up to the dose levels of $9 \mathrm{kGy}$. Additionally, Pinela et al. [24] found that irradiation of Rumex induratus leaves with 1,2 , and $6 \mathrm{kGy}$ had a significant effect on the fat content.

Regarding the effect of gamma irradiation, the different doses induced no significant changes $(p>0.05)$ in the moisture, fat, and ash contents. Our findings revealed that the effect of gamma irradiation on proximate composition is not dose-specific. This finding is generally in agreement with that of the previous study on ash content of chyawanprash [27].

3.2. Mineral Content. As reported in the literature, stevia is a good source of minerals ( $\mathrm{K}, \mathrm{Ca}, \mathrm{Na}, \mathrm{Mg}, \mathrm{Cu}, \mathrm{Mn}$, etc.) [28]. Table 1 shows the results of the effect of freeze-drying and gamma irradiation on the mineral elements, i.e., calcium, potassium, zinc, iron, phosphorus, and manganese, in stevia leaves. The results showed that stevia (commercial, freezedried, and irradiated) contains potassium and calcium as highlighted elements, which are in agreement with the findings of Lemus-mondaca et al. [11]. Potassium aids in the maintenance of normal fluid and mineral balance in the control of blood pressure. Calcium aids in the formation of strong bones and teeth [29].

The results indicated that freeze-drying and gamma irradiation treatments caused no significant changes $(p>0.05)$ in $\mathrm{Ca}, \mathrm{P}$, and $\mathrm{Zn}$ contents, while they caused fluctuations in the $\mathrm{Mn}, \mathrm{Fe}$, and $\mathrm{K}$ contents $(p \leq 0.05)$ (Table 1). Potassium and iron concentration levels were higher in this study for freeze-dried and irradiated stevia, respectively. Moreover, the manganese levels in the freeze-dried and irradiated samples were significantly higher. Similarly, Sanni et al. [30] found that gamma irradiation increased the presence of magnesium, calcium, iron, and manganese in the treated samples of sorrel seeds (Hibiscus sabdariffa) and decreased the presence of sodium, potassium, lead, and copper when the increase in the dose of irradiation was observed. However, Bamidele and Akanbi [31] reported that gamma irradiation has no significant effect on mineral content of the pigeon pea flour. For all mineral elements, the values had no observable trends with increasing irradiation doses. In contrast, Hassan et al. [32] studied the effect of gamma irradiation on the levels of calcium, phosphorus, and iron in peanut at doses of 1.0, 1.5, and $2.0 \mathrm{kGy}$ and reported that there was a gradual increase in the levels of these minerals with increasing irradiation doses. 
TABle 1: Proximate composition (g/100 g) and mineral elements $(\mathrm{mg} / \mathrm{kg} \mathrm{dm})$ of commercial, freeze-dried, and gamma-irradiated stevia.

\begin{tabular}{|c|c|c|c|c|c|}
\hline & \multirow{2}{*}{ Commercial (C) } & \multirow{2}{*}{ Freeze-dried (FD) } & \multicolumn{3}{|c|}{ Gamma-irradiated (GI) } \\
\hline & & & $0.5 \mathrm{kGy}$ & $1 \mathrm{kGy}$ & $2 \mathrm{kGy}$ \\
\hline Moisture content & $9.93 \pm 0.9^{\mathrm{a}}$ & $6.86 \pm 0.2^{c}$ & $8.99 \pm 0.9^{\mathrm{b}}$ & $9.22 \pm 0.9^{\mathrm{b}}$ & $8.89 \pm 1^{\mathrm{b}}$ \\
\hline Fat content & $3.41 \pm 0.04^{\mathrm{a}}$ & $2.34 \pm 0.03^{\mathrm{b}}$ & $2.13 \pm 0.03^{\mathrm{c}}$ & $1.96 \pm 0.02^{\mathrm{c}}$ & $1.63 \pm 0.02^{c}$ \\
\hline Ash content & $8.72 \pm 1^{\mathrm{a}}$ & $9.12 \pm 0.9^{\mathrm{a}}$ & $8.49 \pm 0.8^{\mathrm{a}}$ & $8.58 \pm 0.8^{\mathrm{a}}$ & $9.36 \pm 1^{\mathrm{a}}$ \\
\hline Mineral content (ppm) K & $4458 \pm 38^{\mathrm{c}}$ & $9000 \pm 50^{\mathrm{a}}$ & $7819 \pm 53^{b}$ & $7796 \pm 37^{\mathrm{b}}$ & $7633 \pm 56^{\mathrm{b}}$ \\
\hline $\mathrm{Ca}$ & $8360 \pm 48^{\mathrm{a}}$ & $9104 \pm 55^{\mathrm{a}}$ & $9614 \pm 55^{\mathrm{a}}$ & $8943 \pm 52^{\mathrm{a}}$ & $8940 \pm 53^{\mathrm{a}}$ \\
\hline $\mathrm{P}$ & $1031 \pm 41^{\mathrm{a}}$ & $1091 \pm 43^{\mathrm{a}}$ & $1041 \pm 41^{\mathrm{a}}$ & $1024 \pm 42^{\mathrm{a}}$ & $1038 \pm 46^{\mathrm{a}}$ \\
\hline $\mathrm{Mn}$ & $304 \pm 18^{\mathrm{b}}$ & $402 \pm 21^{\mathrm{a}}$ & $483 \pm 21^{\mathrm{a}}$ & $443 \pm 19^{\mathrm{a}}$ & $431 \pm 25^{\mathrm{a}}$ \\
\hline $\mathrm{Fe}$ & $541 \pm 17^{\mathrm{b}}$ & $515 \pm 15^{\mathrm{b}}$ & $954 \pm 22^{\mathrm{a}}$ & $950 \pm 17^{\mathrm{a}}$ & $945 \pm 24^{\mathrm{a}}$ \\
\hline $\mathrm{Zn}$ & $36 \pm 2^{\mathrm{a}}$ & $34 \pm 2^{\mathrm{a}}$ & $39 \pm 2^{\mathrm{a}}$ & $37 \pm 2^{\mathrm{a}}$ & $32 \pm 2^{\mathrm{a}}$ \\
\hline
\end{tabular}

The results are presented as the mean \pm standard deviation $(\mathrm{SD} ; n=3)$. Different letters in the same row indicate significant differences at $p \leq 0.05$.

The significant differences in mineral content found between the samples were most probably not an effect of the preservation method, but this might be due to a heterogeneous distribution of the minerals in the analysed sample. It could also mean that the minerals are not evenly distributed in the different plant tissues of stevia [33].

3.3. FTIR Analysis. The presence of functional groups in commercial and processed stevia samples was analysed by FTIR spectroscopy. In general, FTIR profiles from the different stevia leaves (Figure 1) indicated the presence of the peak near $3417 \mathrm{~cm}^{-1}\left(3200-3550 \mathrm{~cm}^{-1}\right)$, mainly due to the $\mathrm{C}-\mathrm{O}-\mathrm{H}$ bending vibrations, which is associated with the presence of the hydrogen bond [34]. The stevia FTIR spectrum also showed asymmetric and symmetric stretching vibrations of $\mathrm{sp}^{3}-\mathrm{CH}$ appearing at 2926 and $2870 \mathrm{~cm}^{-1}$ $[35,36]$. The low intensity band, which was recorded at $1730 \mathrm{~cm}^{-1}$, is assigned to the stretching vibration of the ${ }^{-} \mathrm{C}=\mathrm{O}$ bond $\left({ }^{-} \mathrm{C}=\mathrm{O}\right.$ stretching), and this is due to the presence of steviol glycosides, which also have the characteristic band [34]. The band around $1643 \mathrm{~cm}^{-1}$ is also assigned to the stretching vibration of the ${ }^{-} \mathrm{C}=\mathrm{O}$ bond (-C=O stretching). Furthermore, the bands at $1441 \mathrm{~cm}^{-1}$ and $1359 \mathrm{~cm}^{-1}$ correspond to the bending vibration of the $\mathrm{CH}$ bond $\left(1470-1350 \mathrm{~cm}^{-1}\right)$. Finally, the FTIR spectra of the samples showed bands at 1154,1072 , and $1024 \mathrm{~cm}^{-1}$, which are characteristic absorption bands of the steviol glycosides [34].

Based on the obtained FTIR spectra, the applied preservation methods led to a similar band profile for the studied stevia samples.

3.4. Microstructure Examination. The effects of different preservation methods on the microstructure of stevia samples were observed under scanning electron microscopy.

From the obtained images (Figure 2), the treatment effects on tissue structure can be observed by comparing all treated leaves. During freeze-drying, the ice sublimation creates pores, the walls of which may shrink due to surface forces. The porous structure, an important symbol for the freeze-dried products, allows for a fast rehydration process because water easily reoccupies the empty spaces $[7,36]$. A similar observation was previously reported for freeze-dried bananas and lemon balm, respectively $[36,37]$.

Regarding gamma irradiation impact, no significant effect with doses of 0.5 and $1 \mathrm{kGy}$ was observed on the microstructure when compared with those in commercial samples [38]. However, irradiation at $2 \mathrm{kGy}$ caused a shape deformation with the breakage of the structure.

A similar result was found for mango irradiated in the $0.5 \mathrm{kGy}$ to $0.75 \mathrm{kGy}$ irradiation dose range; more intact cells were shown [39].

3.5. Chlorophyll Analysis. Color is a key quality factor that influences consumer acceptance and the market value of products [40]. Table 2 shows the obtained values of chlorophyll content of treated and untreated stevia. Our results suggested that freeze-dried leaves showed significantly higher chlorophyll contents before and after 10 months of storage $(p \leq 0.05)$. It was confirmed that freeze-drying led to the maximum retention of chlorophylls ( $\mathrm{Chl} \mathrm{a,} \mathrm{Chl} \mathrm{b)} \mathrm{in}$ Hibiscus sabdariffa leaves [41]. Our results are in agreement with other findings; Branisa et al. [42] reported that freezedrying has less degradation effect on chlorophyll content compared to other thermal methods used for drying of Melissa officinalis and Urtica dioica. Yu et al. [43] had shown that freeze-dried asparagus has high contents of $\mathrm{Chl}$ a and Chl b compared to vacuum-dried, infrared-dried, or hot-airdried samples.

It has been suggested that the freeze-drying process resulted in the formation of ice crystals and caused rupturing of cell structures leading to better solvent access and extraction [42].

There are few studies analysing the behaviour of gamma radiation on chlorophyll in plants and the levels of these compounds during storage. In this study, the effects of irradiation and storage on chlorophyll content are also indicated. Significant decreases in chlorophylls a and b were observed at $0.5,1$, and $2 \mathrm{kGy}$. Our data are in agreement with the results of previous work where the concentrations of chlorophylls a and b were lower in irradiated leaves [44]. It has been reported that the chlorophyll content in plants gradually decreases after irradiation, which may result from the release of chlorophyll from its protein complex, followed by dephytinization and possibly pheophytinization [45]. The 


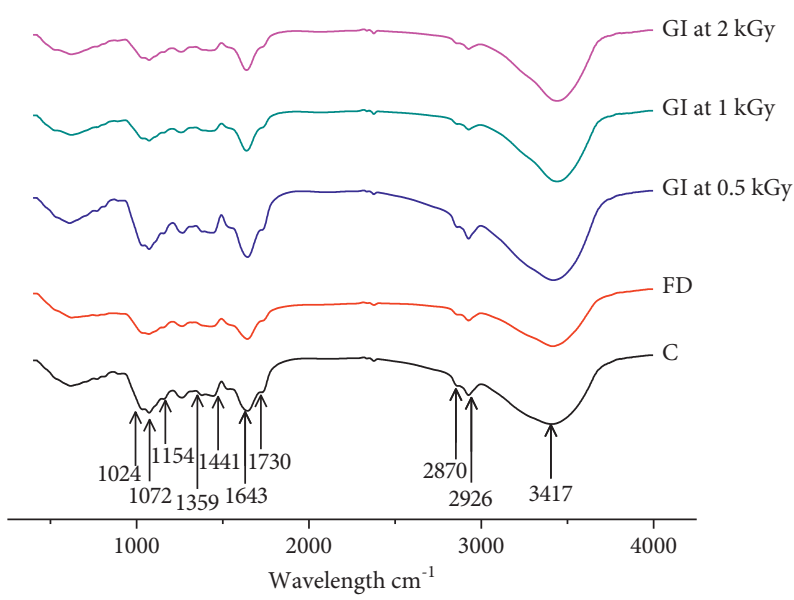

FIGURE 1: FTIR spectra of stevia leaves. C: commercial; FD: freeze-dried; GI: gamma-irradiated.

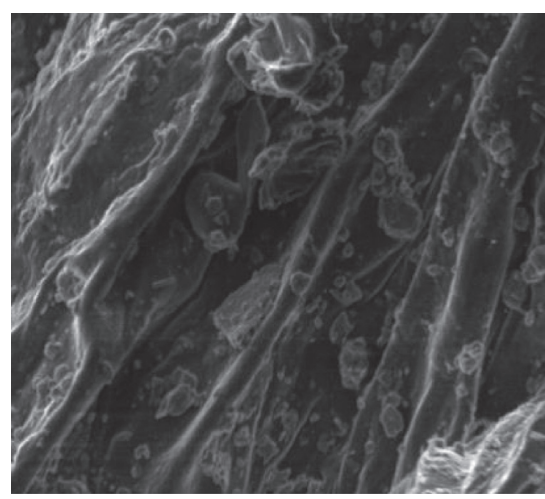

(a)

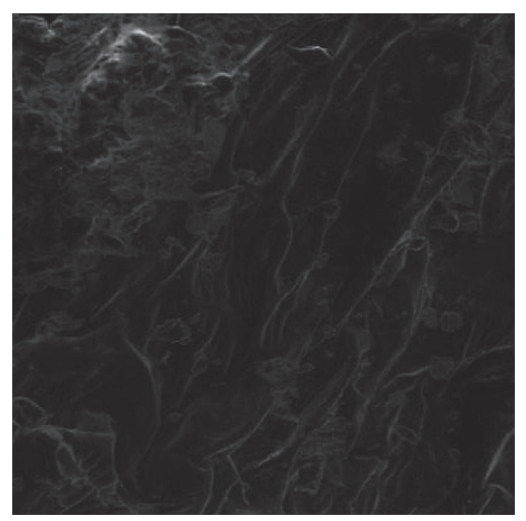

(d)

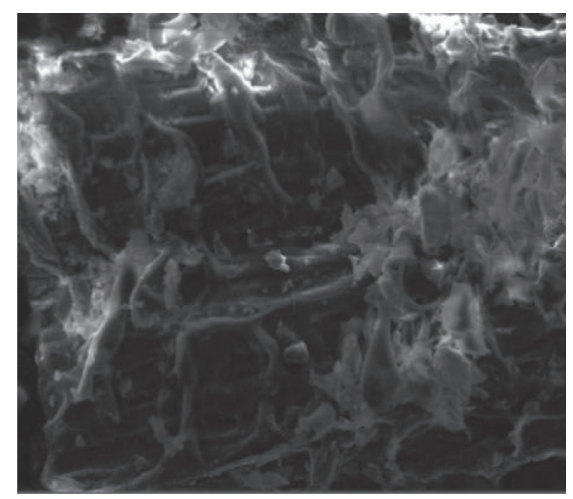

(b)

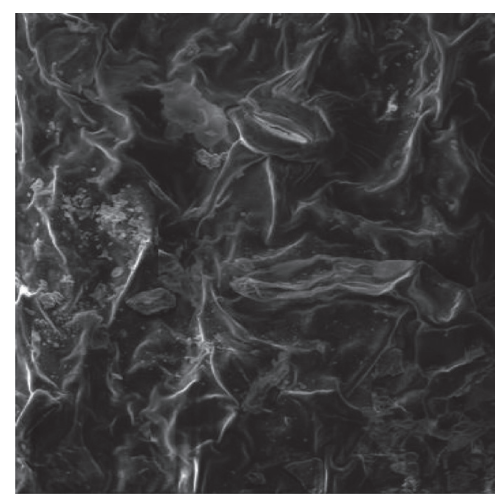

(c)

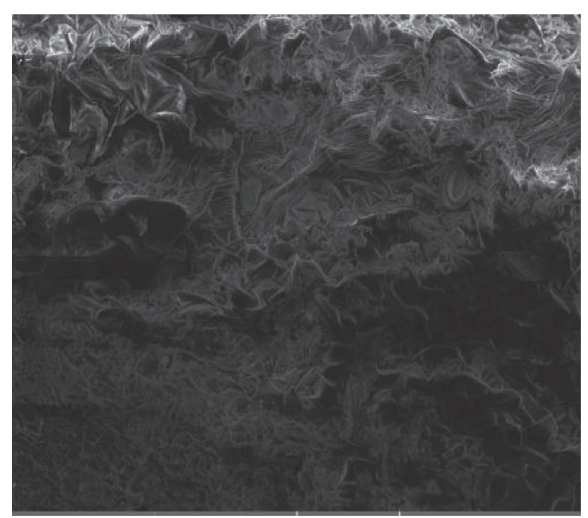

(e)

FIGURE 2: Surface microstructure of stevia leaves: (a) commercial; (b) freeze-dried; (c) gamma-irradiated at 0.5 kGy; (d) gamma-irradiated at $1 \mathrm{kGy}$; (e) gamma-irradiated at $2 \mathrm{kGy}$.

results also suggested that storage had a major impact on chlorophyll content. Chlorophylls a and b decreased when storage progressed; this decrease is probably related to the action of chlorophyllase. Similarly, it was confirmed that total chlorophyll and chlorophyll a decreased as storage progressed [46].

Some studies reported the effect of drying methods on the color and pigment content of stevia leaves. Abou-arab et al. [47] indicated values of $10.1,6.6,3.9$, and $20.1 \mathrm{~g} \mathrm{~g}^{-1}$ of chlorophylls a, b, carotenoids, and total pigments, respectively. Additionally, in the same study, after sun-drying at temperatures between 25 and $30^{\circ} \mathrm{C}$ for 24 to $48 \mathrm{~h}$, final values of $4.7,2.7,0.76$, and $7.5 \mathrm{~g} \mathrm{~g}^{-1}$ of chlorophylls a, b, carotenoids, and total pigments were found.

3.6. Determination of Total Phenolic Content (TPC). Phenolics are aromatic secondary plant metabolites widely spread throughout the plant kingdom and associated with 
TABLE 2: Influence of different preservation treatments and storage period on chlorophyll content of stevia leaves.

\begin{tabular}{lcc}
\hline & Chl a $(\mathrm{mg} / \mathrm{g})$ & Chl b $(\mathrm{mg} / \mathrm{g})$ \\
\hline Before storage & & $5.94 \pm 0.5^{\mathrm{b}}$ \\
$\mathrm{C}$ & $13.72 \pm 0.6^{\mathrm{b}}$ & $6.07 \pm 0.17^{\mathrm{a}}$ \\
FD & $19.51 \pm 0.6^{\mathrm{a}}$ & $4.55 \pm 0.2^{\mathrm{ac}}$ \\
GI at $0.5 \mathrm{kGy}$ & $10.69 \pm 0.5^{\mathrm{c}}$ & $3.88 \pm 0.2^{\mathrm{c}}$ \\
GI at $1 \mathrm{kGy}$ & $9.2 \pm 0.2^{\mathrm{c}}$ & $4.76 \pm 0.1^{\mathrm{c}}$ \\
GI at $2 \mathrm{kGy}$ & $7.17 \pm 0.2^{\mathrm{d}}$ & \\
\hline After 10 months of storage & & $2.39 \pm 0.09^{\mathrm{d}}$ \\
C & $6.38 \pm 0.3^{\mathrm{e}}$ & $4.83 \pm 0.4^{\mathrm{c}}$ \\
FD & $10.01 \pm 0.5^{\mathrm{c}}$ & $1.76 \pm 0.01^{\mathrm{d}}$ \\
GI at $0.5 \mathrm{kGy}$ & $2.77 \pm 0.2^{\mathrm{f}}$ & $1.34 \pm 0.01^{\mathrm{d}}$ \\
GI at $1 \mathrm{kGy}$ & $2.00 \pm 0.2^{\mathrm{f}}$ & $1.21 \pm 0.01^{\mathrm{d}}$ \\
GI at $2 \mathrm{kGy}$ & $2.50 \pm 0.2^{\mathrm{f}}$ & \\
\hline
\end{tabular}

The results are expressed as mean \pm standard deviation. Different letters in the same column indicate significant statistical differences. The significant differences at a level of 5\% were performed by Tukey's test. C: commercial; FD: freeze-dried; GI: gamma-irradiated.

color, sensory qualities, and nutritional and antioxidant properties of foods [41]. The TPC as affected by preservation methods and storage time is shown in Figure 3. As can be seen, the content of total polyphenols varied with the method of preservation and the storage time.

On day 0 of storage (before storage), the highest content of phenolic compounds is found for freeze-dried leaves. Other studies have also documented that freeze-drying increases the extraction of bioactive compounds compared to hot-air-drying $[42,48]$. It has been suggested that lyophilization resulted in the formation of ice crystals and caused the breakdown of cellular structures leading to better solvent access and better extraction [49].

It is speculated that the temperature of freeze-drying, as low as $-50^{\circ} \mathrm{C}$ in the present study, is beneficial for maintaining the stability of polyphenols in the sample, which resulted in a high total polyphenol content in the freezedried leaves even after 10 months of storage [50].

Considerably variable amounts of TPC in stevia leaves were previously reported: $25.18 \mathrm{mg}$ gallic acid equivalent (GAE)/g [51]; $56.74 \mathrm{mg} \mathrm{GAE/g,} \mathrm{obtained} \mathrm{with} \mathrm{air-drying}$ [52]; $130.67 \mathrm{mg}$ catechin/g, for air-drying at $40^{\circ} \mathrm{C} / 12 \mathrm{~h}$ [53]; $0.709 \mathrm{mg}$ GAE/g of dry sample [54]; and 20.85 and $22.25 \mathrm{mg}$ $\mathrm{GAE} / \mathrm{g}$ for water extract and methanol-water, respectively [55].

Storage time had significant effects on the TPC (Figure 3). Similarly, gamma irradiation exhibited a profound influence on TPC content, and an increase of irradiation doses has been reported to significantly increase the amounts of TPC for irradiated stevia leaves. This increase may be related to the effect of irradiation, which affects chemical bonds and consequently induces the release of low-molecular-weight fragments [19, 23]. Likewise, other studies have correlated this change with the activation of the biosynthesis of phenylalanine ammonia-lyase (PAL) as a regulatory enzyme in the biosynthesis of phenolic compounds [23]. There was a significant difference between TPC levels before and after storage for both preservation processes $(p \leq 0.05)$, compared with control (commercial). Depolymerization of the cell wall polysaccharides, alteration of the membrane integrity, and decomposing the insoluble phenolics as a result of irradiation could also be the reasons for the increase of soluble phenolic compounds [56].

3.7. Antioxidant Properties. The results of antioxidant activity of stevia leaves are presented in Figure 4. For the DPPH radical scavenging activity in the commercial, freeze-dried, and gamma-irradiated stevia leaves, significant differences were observed, regardless of whether before and after 10 months of storage. Additionally, a significant increase for stored samples was observed.

Regarding the preservation method, DPPH radical scavenging activity was significantly increased in irradiated leaves. Indeed, whether it be before or after storage, gammairradiated samples had the highest DPPH scavenging activity, followed by the freeze-dried one which was higher than the commercial one. A significant increase was observed as the irradiation dose increased.

In this study, gamma-irradiated leaves had the strongest antioxidant capacity, which was related to the retention of more phenolic compounds. Our results agree with those obtained by Variyar et al. [57] whom found that the radical scavenging ability of gamma-irradiated soybean, between 0.5 and $5 \mathrm{kGy}$ on DPPH radicals, increased dosedependently. On the contrary, they differ from what Woon Lee et al. [58] had demonstrated that, in fresh ready-to-use tamarind juice, a non-significant increase in DPPH scavenging activity was observed as the irradiation dose increased, and a significant increase with stored samples was revealed. Among drying methods, freeze-drying has already been reported to retain the maximum antioxidant potential referenced to polyphenol compounds in leafy extracts of dried herbs [42].

Several studies reported that stevia leaves have a good DPPH radical scavenging activity. Shukla et al. [59] studied the antioxidant activity of ethanolic extracts from stevia leaves which exert a higher antioxidant activity when compared to ascorbic acid and against DPPH $\left(\mathrm{IC}_{50}=93.46 \mu \mathrm{g} / \mathrm{mL}\right)$. The DPPH radical scavenging activity as affected by air-drying methods was studied, and the 


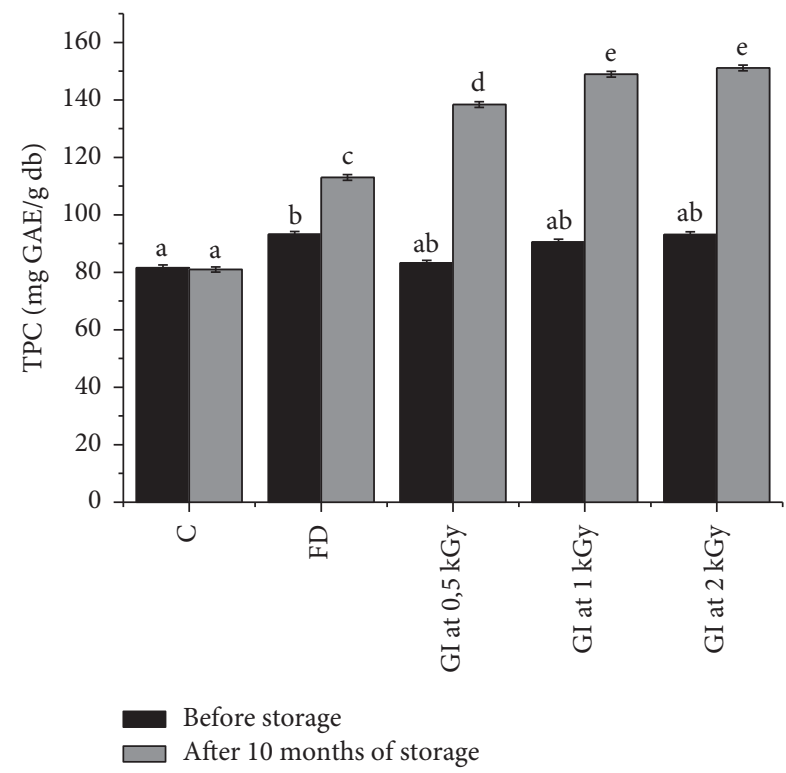

FIgUre 3: Total phenolic content of stevia leaves subjected to different preservation treatments and storage period. Values are the mean $\pm \mathrm{SD}$ of three replicates and significant at $p \leq 0.05$. C: commercial; FD: freeze-dried; GI: gamma-irradiated.

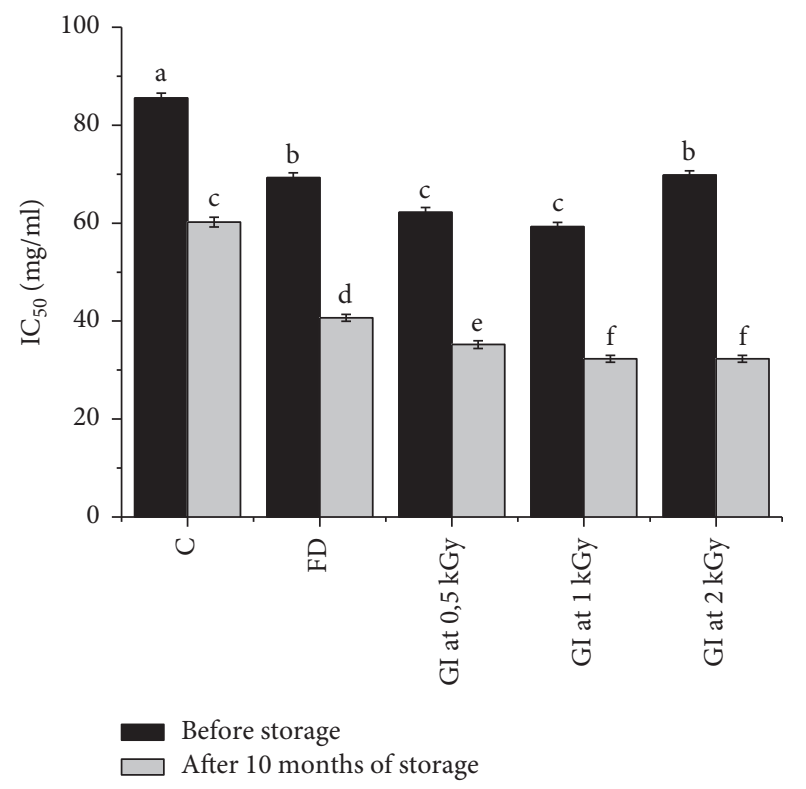

Figure 4: DPPH free-radical scavenging activity of differently preserved stevia leaves as influenced by storage time. Values are the mean $\pm S D$ of three replicates and significant at $p \leq 0.05$. C: commercial; FD: freeze-dried; GI: gamma-irradiated.

amount of antioxidants found for hot-air-drying at $180^{\circ} \mathrm{C}$, shade-drying, hot-air-drying at $100^{\circ} \mathrm{C}$, and freeze-drying was $126 \mathrm{mg}$ Trolox equivalent/g, $75.9 \mathrm{mg}$ Trolox equivalent/g, $64.9 \mathrm{mg}$ Trolox equivalent/g, and $48.5 \mathrm{mg}$ Trolox equivalent/ $g$ stevia [13]. The radical scavenging effect of the water extract and methanol-water extract determined by the DPPH test was 5.00 and $2.90(\mathrm{mg}$ of vitamin $\mathrm{C} / \mathrm{mL})$, respectively [55].
One should bear in mind that the presented results of antioxidant capacity are related to the DPPH assay and the resulting antioxidant potential can be influenced by the nature of solvent as well as the extraction method [42].

\section{Conclusion}

Freeze-drying and gamma irradiation are conventional methods for preserving medicinal and aromatic plants. The purpose of this study was to investigate the effects of these preservation methods on the physicochemical and surface properties of stevia leaves. Generally, gamma irradiation has been documented in the literature as a processing technique to improve the microbiological quality and safety of medicinal and aromatic plants.

In this study, stevia leaves showed better quality after gamma irradiation at low doses in terms of the content of total polyphenols and antioxidants. Therefore, gamma irradiation can be applied to alleviate any problem related to stevia postharvest contamination.

Moreover, our results allow us to consider lyophilization, despite its higher cost, to be a more effective drying method for reasons of preserving chlorophylls and polyphenol compounds as well as in terms of antioxidant capacity. Thus, both freeze-drying and gamma irradiation could be potential postharvest methods for obtaining high-quality stevia leaves; these processes positively affect bioactive compounds and antioxidant activity even after ten months of storage.

\section{Data Availability}

The data used to support the findings of this study are available from the corresponding author upon request.

\section{Conflicts of Interest}

The authors declare that there are no conflicts of interest.

\section{Acknowledgments}

The authors are grateful to the MESRSFC and the CNRST of the Kingdom of Morocco in the priority areas of research valorization scientific and technological by innovation of local products: aromatic and medicinal plants in IAA and ICPC (R2BINNOVA) CODE: PPR-B-R2BINOV-MahrouzFSUCA-Marrakech, for the financial support of this study. The authors also would like to acknowledge MOGADOR Cooperative (Essaouira, Morocco) for kindly providing the stevia plant material.

\section{References}

[1] L. G. Angelini, A. Martini, B. Passera, and S. Tavarini, Cultivation of Stevia Rebaudiana Bertoni and Associated Challenges, J.-M. Mérillon and K. G. Ramawat, Eds., Springer, Berlin, Germany, pp. 35-85, 2018.

[2] M. F. Jahangir Chughtai, I. Pasha, T. Zahoor et al., "Nutritional and therapeutic perspectives of Stevia rebaudiana as emerging sweetener; a way forward for sweetener industry," CyTA-Journal of Food, vol. 18, no. 1, pp. 164-177, 2020. 
[3] S. Sharma, S. Walia, B. Singh, and R. Kumar, "Comprehensive review on agro technologies of low-calorie natural sweetener stevia (Stevia rebaudiana Bertoni): a boon to diabetic patients," Journal of the Science of Food and Agriculture, vol. 96, no. 6, pp. 1867-1879, 2016.

[4] E. Perez, C. Gonzalez, F. Vaillant, and M. Lares, "Stevia derivative and its potential uses in diabetic-directed foods. Review," Journal of Nutrients, vol. 3, no. 1, pp. 1-20, 2016.

[5] A. Aboudrare, "Une nouvelle plante sucrée au Maroc. Stevia rebaudiana," PNTTA. Transf. Technol. En Agric.vol. 174, pp. 1-6, 2009.

[6] B. F. Dababneh, "An innovative microwave process for microbial decontamination of spices and herbs," African Journal of Microbiology Research, vol. 7, pp. 636-645, 2013.

[7] X. Duan, X. Yang, G. Ren, Y. Pang, L. Liu, and Y. Liu, "Technical aspects in freeze-drying of foods," Drying Technology, vol. 34, no. 11, pp. 1271-1285, 2015.

[8] L. Li, M. Zhang, B. Chitrakar, and H. Jiang, "Effect of combined drying method on phytochemical components, antioxidant capacity and hygroscopicity of Huyou (Citrus changshanensis) fruit," Lebensmittel-Wissenschaft \& Technologie, vol. 123, pp. 109102-102, 2020.

[9] M. H. Rashid, M. A. Z. Chowdhury, Z. Fardous et al., "Microbial decontamination of gamma irradiated black tea and determination of major minerals in black tea, fresh tea leaves and tea garden soil," Lebensmittel-Wissenschaft \& Technologie, vol. 73, pp. 185-190, 2016.

[10] A. M. A. Osman, A. B. Hassan, G. A. M. Osman et al., "Effects of gamma irradiation and/or cooking on nutritional quality of faba bean (Vicia faba L.) cultivars seeds," Journal of Food Science \& Technology, vol. 51, no. 8, pp. 1554-1560, 2014.

[11] R. Lemus-mondaca, A. Vega-gálvez, P. Rojas, and K. Ah-hen, "Assessment of quality attributes and steviosides of Stevia rebaudiana leaves subjected to different drying methods," J. Food Nutr. Res, vol. 4, pp. 720-728, 2016.

[12] M. A. Abdalbasit Gasmalla, R. Yang, A. Musa, X. Hua, and W. Zhang, "Physico-chemical assessment and rebauidioside A. Productively of natural sweeteners (stevia rebaudiana bertoni)," Journal of Food and Nutrition Research, vol. 2, no. 5, pp. 209-214, 2014.

[13] A. Periche, M. L. Castelló, A. Heredia, and I. Escriche, "Influence of drying method on steviol glycosides and antioxidants in Stevia rebaudiana leaves," Food Chemistry, vol. 172, pp. 1-6, 2015.

[14] N. Hidar, M. Ouhammou, S. Mghazli et al., "The impact of solar convective drying on kinetics, bioactive compounds and microstructure of stevia leaves," Renewable Energy, vol. 161, pp. 1176-1183, 2020.

[15] X. Huang, W. Li, Y. Wang, and F. Wan, "Drying characteristics and quality of Stevia rebaudiana leaves by far-infrared radiation," Lebensmittel-Wissenschaft \& Technologie, vol. 140, Article ID 110638, 2021.

[16] E. Pereira, A. L. Antonio, A. Rafalski, J. C. M. Barreira, L. Barros, and I. C. F. R. Ferreira, "Extending the use of irradiation to preserve chemical and bioactive properties of medicinal and aromatic plants: a case study with four species submitted to electron beam," Industrial Crops and Products, vol. 77, pp. 972-982, 2015.

[17] H. Machhour, I. El Hadrami, B. Imziln, M. Mouhib, and M. Mahrouz, "Microbial decontamination by low dose gamma irradiation and its impact on the physico-chemical quality of peppermint (Mentha piperita)," Radiation Physics and Chemistry, vol. 80, no. 4, pp. 604-607, 2011.
[18] S. Zantar, R. Haouzi, M. Chabbi et al., "Effect of gamma irradiation on chemical composition, antimicrobial and antioxidant activities of Thymus vulgaris and Mentha pulegium essential oils," Radiation Physics and Chemistry, vol. 115, pp. 6-11, 2015.

[19] S. Mghazli, Etude d'un nouveau éco-procédé de conservation des feuilles de Rosmarinus officinalis en comparaison avec la technologie d'ionisation par rayonnement gamma: Etude des propriétés physico-chimiques, thérapeutiques et hygiéniques, Université Cadi Ayyad, Marrakesh, Morocco, 2018.

[20] L. Lahnine, S. Mghazli, M. Mahrouz et al., "Decontamination by gamma irradiation at low doses of Thymus satureioides and its impact on physico-chemical quality," Food and Bioproducts Processing, vol. 104, pp. 48-56, 2017.

[21] AOAC, Official Methods of Analysis, Association of Official Analytical Chemists, Washington, DC, USA, 16th ed. edition, 1997.

[22] J. C. R. Ruiz, Y. B. M. Ordoñez, Á. M. Basto, and M. R. S. Campos, "Antioxidant capacity of leaf extracts from two Stevia rebaudiana Bertoni varieties adapted to cultivation in Mexico," Nutricion Hospitalaria, vol. 31, pp. 1163-1170, 2015.

[23] L. Lahnine, Étude comparative de deux procédés de conservation thermobiochimique et irradiation gamma de la qualité physicochimique et hygiénique du Thymus satureioides, Université Cadi Ayyad, Marrakesh, Morocco, 2017.

[24] J. Pinela, J. C. M. Barreira, L. Barros et al., "Modified atmosphere packaging and post-packaging irradiation of Rumex induratus leaves: a comparative study of postharvest quality changes," Journal of Food Science \& Technology, vol. 53, no. 7, pp. 2943-2956, 2016.

[25] A. Cheng, F. Wan, T. Xu, F. Du, W. Wang, and Q. Zhu, "Effect of irradiation and storage time on lipid oxidation of chilled pork," Radiation Physics and Chemistry, vol. 80, no. 3, pp. 475-480, 2011.

[26] K. F. Khattak, "Proximate composition, phytochemical profile and free radical scavenging activity of radiation processed Emblica officinalis," International Food Research Journal, vol. 20, pp. 1125-1131, 2013.

[27] A. Ramathilaga and A. G. Murugesan, "Effect of electron beam irradiation on proximate, microbiological and sensory characteristics of chyavanaprash - ayurvedic poly herbal formulation," Innovative Food Science \& Emerging Technologies, vol. 12, no. 4, pp. 515-518, 2011.

[28] R. Lemus-Mondaca, A. Vega-Gálvez, L. Zura-Bravo, and K. Ah-Hen, "Stevia rebaudiana Bertoni, source of a highpotency natural sweetener: a comprehensive review on the biochemical, nutritional and functional aspects," Food Chemistry, vol. 132, no. 3, pp. 1121-1132, 2012.

[29] N. K. Kortei, G. T. Odamtten, M. Obodai, M. Wiafe-Kwagyan, E. A. Addo, and E. A. Addo, "Influence of low dose of gamma radiation and storage on some vitamins and mineral elements of dried oyster mushrooms (Pleurotus ostreatus)," Food Sciences and Nutrition, vol. 5, no. 3, pp. 570-578, 2016.

[30] T. A. Sanni, J. Ogundele, E. Ogunbusola, and O. Oladimeji, "Effect of gamma irradiation on mineral, vitamins and cooking properties of sorrel (Hibiscus sabdariffa L1) seeds," in Proceedings of the 2nd International Conference on Chemical Biological Environmental Sciences, pp. 17-21, Dubai (UAE), May 2015.

[31] O. P. Bamidele and C. T. Akanbi, "Effect of gamma irradiation on physicochemical properties of stored pigeon pea (C ajanus cajan) flour," Food Sciences and Nutrition, vol. 1, no. 5, pp. 377-383, 2013. 
[32] A. B. Hassan, E. E. Diab, N. S. Mahmoud, R. A. A. Elagib, M. A. H. Rushdi, and G. A. M. Osman, "Effect of radiation processing on in vitro protein digestibility and availability of calcium, phosphorus and iron of peanut," Radiation Physics and Chemistry, vol. 91, pp. 200-202, 2013.

[33] R. Lemus-mondaca, K. Ah-hen, A. Vega-Gálvez, C. Honores, and N. O. Moraga, "Stevia rebaudiana leaves: effect of drying process temperature on bioactive components, antioxidant capacity and natural sweeteners," Plant Foods for Human Nutrition, vol. 71, no. 1, pp. 49-56, 2015.

[34] C. Chranioti, S. Chanioti, and C. Tzia, "Comparison of spray, freeze and oven drying as a means of reducing bitter aftertaste of steviol glycosides (derived from Stevia rebaudiana Bertoni plant) - evaluation of the final products," Food Chemistry, vol. 190, pp. 1151-1158, 2016.

[35] S. Pacifico, S. Piccolella, P. Nocera, E. Tranquillo, F. Dal Poggetto, and M. Catauro, "Steviol glycosides content in cultivated Stevia rebaudiana Bertoni: a new sweet expectation from the Campania region (Italy)," Journal of Food Composition and Analysis, vol. 63, pp. 111-120, 2017.

[36] A. R. Andino, F. Pieniazek, and V. Messina, "Texture of bananas submitted to different freeze drying cycle applying scanning electron microsocopy with image analysis techniques," Food Biophysics, vol. 14, no. 1, pp. 13-21, 2018.

[37] D. Argyropoulos and J. Müller, "Effect of convective-, vacuum- and freeze drying on sorption behaviour and bioactive compounds of lemon balm (Melissa officinalis L.)," Journal of Applied Research on Medicinal and Aromatic Plants, vol. 1, no. 2, pp. 59-69, 2014.

[38] K. Akram, J.-J. Ahn, and J.-H. Kwon, "Identification and characterization of gamma-irradiated dried lentinus edodes using ESR, SEM, and FTIR analyses," Journal of Food Science, vol. 77, no. 6, pp. C690-C696, 2012.

[39] S. Ghosh and M. K. Das, "Optimization of the effect of gamma radiation on textural properties of different varieties of potato (Kufri Chandramukhi and Kufri Jyoti) and mango (Langra and Fazli) during storage by Response Surface Methodology," Innovative Food Science \& Emerging Technologies, vol. 26, pp. 257-264, 2014.

[40] Y. Tian, Y. Zhao, J. Huang, H. Zeng, and B. Zheng, "Effects of different drying methods on the product quality and volatile compounds of whole shiitake mushrooms," Food Chemistry, vol. 197, pp. 714-722, 2016.

[41] S. S. Kumar, P. Manoj, N. P. Shetty, and P. Giridhar, "Effect of different drying methods on chlorophyll, ascorbic acid and antioxidant compounds retention of leaves ofHibiscus sabdariffaL," Journal of the Science of Food and Agriculture, vol. 95, no. 9, pp. 1812-1820, 2015.

[42] J. Branisa, K. Jomova, M. Porubska, V. Kollar, M. Simunkova, and M. Valko, "Effect of drying methods on the content of natural pigments and antioxidant capacity in extracts from medicinal plants: a spectroscopic study," Chemical Papers, vol. 71, no. 10, pp. 1993-2002, 2017.

[43] Q. Yu, J. Li, and L. Fan, "Effect of drying methods on the microstructure, bioactivity substances, and antityrosinase activity of asparagus stems," Journal of Agricultural and Food Chemistry, vol. 67, no. 5, pp. 1537-1545, 2019.

[44] D. Marcu, G. Damian, C. Cosma, and V. Cristea, "Gamma radiation effects on seed germination, growth and pigment content, and ESR study of induced free radicals in maize (Zea mays)," Journal of Biological Physics, vol. 39, no. 4, pp. 625-634, 2013.
[45] P. Saha, S. Sen Raychaudhuri, A. Chakraborty, and M. Sudarshan, "PIXE analysis of trace elements in relation to chlorophyll concentration in Plantago ovata Forsk," Applied Radiation and Isotopes, vol. 68, no. 3, pp. 444-449, 2010.

[46] W.-Y. Hsu, A. Simonne, P. Jitareerat, and M. R. Marshall Jr., "Low-dose irradiation improves microbial quality and shelf life of fresh mint (Mentha piperita L.) without compromising visual quality," Journal of Food Science, vol. 75, no. 4, pp. M222-M230, 2010.

[47] A. E. Abou-arab, A. A. Abou-arab, and M. F. Abu-salem, "Physico-chemical assessment of natural sweeteners steviosides produced from Stevia rebaudiana bertoni plant," African Journal of Food Science, vol. 4, pp. 269-281, 2010.

[48] J. Pinela, L. Barros, M. Dueñas, A. M. Carvalho, C. SantosBuelga, and I. C. F. R. Ferreira, "Antioxidant activity, ascorbic acid, phenolic compounds and sugars of wild and commercial Tuberaria lignosa samples: effects of drying and oral preparation methods," Food Chemistry, vol. 135, no. 3, pp. 1028-1035, 2012.

[49] K. M. Youssef and S. M. Mokhtar, "Effect of drying methods on the antioxidant capacity, color and phytochemicals of portulaca oleracea L. Leaves," Journal of Nutrition \& Food Sciences, vol. 4, no. 6, 2014.

[50] A.-W. Cheng, H.-X. Xie, Y. Qi et al., "Effects of storage time and temperature on polyphenolic content and qualitative characteristics of freeze-dried and spray-dried bayberry powder," Lebensmittel-Wissenschaft \& Technologie, vol. 78, pp. 235-240, 2017.

[51] M. B. Tadhani, V. H. Patel, and R. Subhash, "In vitro antioxidant activities of Stevia rebaudiana leaves and callus," Journal of Food Composition and Analysis, vol. 20, no. 3-4, pp. 323-329, 2007.

[52] S. Shukla, A. Mehta, P. Mehta, and V. K. Bajpai, "Antioxidant ability and total phenolic content of aqueous leaf extract of Stevia rebaudiana Bert," Experimental \& Toxicologic Pathology, vol. 64, no. 7-8, pp. 807-811, 2012.

[53] I.-S. Kim, M. Yang, O.-H. Lee, and S.-N. Kang, "The antioxidant activity and the bioactive compound content of Stevia rebaudiana water extracts," Lebensmittel-Wissenschaft und -Technologie- Food Science and Technology, vol. 44, no. 5, pp. 1328-1332, 2011.

[54] L. Garcia-Mier, A. E. Meneses-Reyes, S. N. Jimenez-Garcia et al., "Polyphenol content and antioxidant activity of stevia and peppermint as a result of organic and conventional fertilization," Journal of Food Quality, vol. 2021, pp. 1-6, 2021.

[55] F. N. Muanda, R. Soulimani, B. Diop, and A. Dicko, "Study on chemical composition and biological activities of essential oil and extracts from Stevia rebaudiana Bertoni leaves," Lebensmittel-Wissenschaft und-Technologie- Food Science and Technology, vol. 44, no. 9, pp. 1865-1872, 2011.

[56] N. S. Najafabadi, M. A. Sahari, M. Barzegar, and Z. H. Esfahani, "Effect of gamma irradiation on some physicochemical properties and bioactive compounds of jujube (Ziziphus jujuba var vulgaris) fruit," Radiation Physics and Chemistry, vol. 130, pp. 62-68, 2017.

[57] P. S. Variyar, A. Limaye, and A. Sharma, "Radiation-induced enhancement of antioxidant contents of soybean (Glycine max merrill)," Journal of Agricultural and Food Chemistry, vol. 52, no. 11, pp. 3385-3388, 2004.

[58] J. W. Lee, J. K. Kim, P. Srinivasan et al., "Effect of gamma irradiation on microbial analysis, antioxidant activity, sugar content and color of ready-to-use tamarind juice during 
storage," Lebensmittel-Wissenschaft und -Technologie- Food Science and Technology, vol. 42, no. 1, pp. 101-105, 2009.

[59] S. Shukla, A. Mehta, V. K. Bajpai, and S. Shukla, "In vitro antioxidant activity and total phenolic content of ethanolic leaf extract of Stevia rebaudiana Bert," Food and Chemical Toxicology, vol. 47, no. 9, pp. 2338-2343, 2009. 